\title{
Effect of charged line defects on conductivity in graphene: Numerical Kubo and analytical Boltzmann approaches
}

\author{
Radchenko, T. M.; Shylau, A. A.; Zozoulenko, I. V.; Ferreira, Aires
}

Published in:

Physical Review B Condensed Matter

Link to article, DOI:

10.1103/PhysRevB.87.195448

Publication date:

2013

Document Version

Publisher's PDF, also known as Version of record

Link back to DTU Orbit

Citation (APA):

Radchenko, T. M., Shylau, A. A., Zozoulenko, I. V., \& Ferreira, A. (2013). Effect of charged line defects on conductivity in graphene: Numerical Kubo and analytical Boltzmann approaches. Physical Review $B$ Condensed Matter, 87(19), 195448. https://doi.org/10.1103/PhysRevB.87.195448

\section{General rights}

Copyright and moral rights for the publications made accessible in the public portal are retained by the authors and/or other copyright owners and it is a condition of accessing publications that users recognise and abide by the legal requirements associated with these rights.

- Users may download and print one copy of any publication from the public portal for the purpose of private study or research.

- You may not further distribute the material or use it for any profit-making activity or commercial gain

- You may freely distribute the URL identifying the publication in the public portal 


\title{
SCREEN PRINTED PZT/PZT THICK FILM BIMORPH MEMS CANTILEVER DEVICE FOR VIBRATION ENERGY HARVESTING
}

\author{
R. Xu ', A. Lei , T.L. Christiansen , K. Hansen , M. Guizzetti , K. Birkelund , E.V. Thomsen ${ }^{1}$ \\ and O. Hansen \\ ${ }^{1}$ Department of Micro- and Nanotechnology, Technical University of Denmark, DTU Nanotech, \\ Building 345 East, DK-2800 Kongens Lyngby, Denmark \\ ${ }^{2}$ Meggitt Sensing Systems, DK-3490 Kvistgaard, Denmark \\ ${ }^{3} \mathrm{CINF}$, Center for Individual Nanoparticle Functionality, Technical University of Denmark
}

\begin{abstract}
We present a MEMS-based PZT/PZT thick film bimorph vibration energy harvester with an integrated silicon proof mass. The most common piezoelectric energy harvesting devices utilize a cantilever beam of a non piezoelectric material as support beneath or in-between the piezoelectric material. It provides mechanical support but it also reduces the power output. Our device replaces the support with another layer of the piezoelectric material, and with the absence of an inactive mechanical support all of the stresses induced by the vibrations will be harvested by the active piezoelectric elements.
\end{abstract}

\section{KEYWORDS}

Energy harvester, MEMS, thick film, PZT, bimorph

\section{INTRODUCTION}

With the recent development in low power electronics and wireless systems it has become increasingly interesting to use energy harvesters that harness ambient energies to empower electronic sensor systems instead of using electrochemical batteries. The limited lifespan of traditional electrochemical batteries requires periodical replacement and the batteries often take up significant volume in the total sensing system. The MEMS energy harvester addresses these two issues by having large energy to volume ratio [1] and by scavenging energies from external sources, thus the lifetime is only limited by material decay or fatigue. This will reduce the frequency of periodic maintenance from months to years, and maybe even decades.

The most common ambient power sources are solar, thermal, mechanical or unused RF energy. Harvesting vibration energy from a mechanical noise source can either be based on electrostatic, electromagnetic or piezoelectric conversion [2]. The interest in harvesting energy from ambient mechanical vibrations has resulted in a number of review articles in recent years [1-4]. In particular the piezoelectric transduction method has received significant attention. A typical piezoelectric energy harvester is based on a bimorph cantilever beam, which consists of the active piezoelectric ceramic with metal electrodes on both side and a passive mechanical support structure, anchored at one end and with a proof mass at the other [5-8].

There are many different piezoelectric materials available, however the materials of most interest for application in MEMS devices are PZT $\left(\mathrm{Pb}\left(\mathrm{Zr}_{\mathrm{x}} \mathrm{Ti}_{1-\mathrm{x}}\right) \mathrm{O}_{3}\right)$, zinc oxide ( $\mathrm{ZnO})$ [9], [10] and aluminium nitride (AIN) [11], [12]. Among these, PZT is the most commonly used in energy harvesters.

Energy harvesters with bulk PZT have been presented in [13] and [14]. These energy harvesters have large dimensions and are thus not compatible with small sensor systems. Energy harvesters made with thin film deposition methods, such as sputtering [15] or sol-gel spin-on [16], [17] are characterized by a very thin layer PZT of just a few micrometers. Fabrication of a pure self supporting PZT beam without any mechanical support structure will be very difficult using these methods. We therefore use thick film screen printing technique, and utilize the advantage of being able to screen print PZT thick film with a thickness of $15 \mu \mathrm{m}$ to $60 \mu \mathrm{m}$ to fabricate energy harvesters with a pure PZT beam [18].

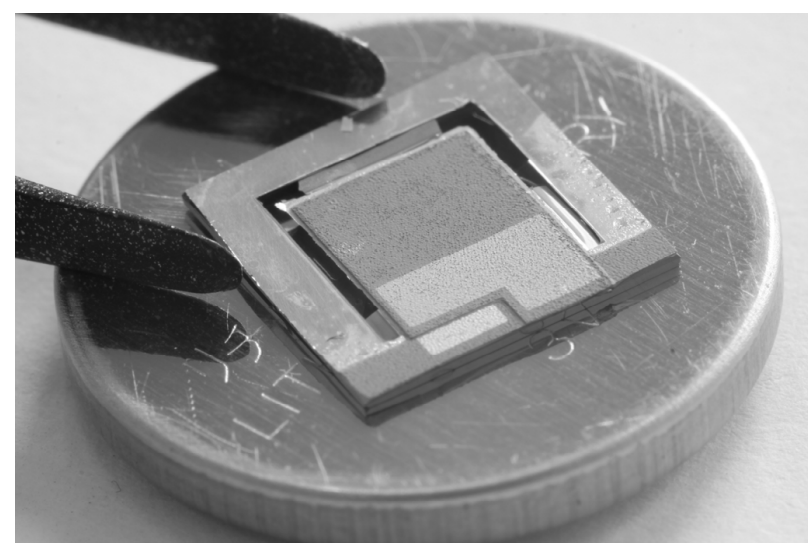

Figure 1: The bimorph MEMS energy harvester on top of a $C R$ 2032 button battery.

In this work the piezoelectric PZT thick film used is InSensor ${ }^{\circledR}$ TF2100; the PZT film was screen printed with a thickness of around $30 \mu \mathrm{m}$. This technique has previously been used in fabrication of a piezoelectric accelerometer [19] and energy harvester [20]. With the use of PZT thick film, instead of PZT thin film, a mechanical support material is no longer needed in the final device, since the beam is thick and strong enough to support the proof mass. The fabricated bimorph cantilever energy harvester depicted in Figure 1 consists of two PZT layers separated by a middle electrode. Here both layers are active and thus the strain energy from both layers is 
harvested [21]. The advantage of such a structure is that all strain energy is harvested, while in conventional structures with inactive support materials the strain energy in these is not harvested and thus wasted.

\section{FABRICATION}

The PZT/PZT thick film energy harvesters are fabricated using a six mask fabrication process on a 4 inch (100 mm) silicon on insulator (SOI) wafer with a $30 \mu \mathrm{m}$ device layer, a $1 \mu \mathrm{m}$ buried oxide layer and a $525 \mu \mathrm{m}$ thick carrier substrate, Figure 2(a). The backside of the SOI wafer is patterned using UV lithography and etched using a DRIE process, Figure 2(b). The buried oxide layer is here used as an etch stop layer. After an RCA clean a 1 $\mu \mathrm{m}$ thick silicon dioxide layer is grown in a furnace by thermal oxidation. This layer will serve as an etch stop for a final RIE etch, releasing the structure, Figure 2(c). The bottom electrode is deposited on the front side of the SOI wafer using e-beam deposition. The bottom electrode layer consists of a $50 \mathrm{~nm}$ titanium adhesion layer and 500 $\mathrm{nm}$ of platinum which also serves as a diffusion barrier in the PZT sintering process. The bottom electrode layer is patterned using UV lithography and etched in a wet etch solution, $\mathrm{H}_{2} \mathrm{O}: \mathrm{HCl}: \mathrm{HNO}_{3}(8: 7: 1)$ at elevated temperature, Figure 2(d). On top of the patterned bottom electrode a 30 $\mu \mathrm{m}$ PZT thick film is deposited using screen printing and sintered (Figure 2(e)). The middle electrode is then deposited through a prefabricated shadow mask using e-beam deposition, Figure 2(f). The shadow mask was made using a $350 \mu \mathrm{m}$ silicon wafer, which was patterned using UV lithograph and etched through in a DRIE process. Then the second layer of PZT thick film is screen printed and sintered. The top electrode layer is similarly deposited through a shadow mask using e-beam deposition, Figure 2(g). With the two PZT stacks in place the silicon device layer can now be removed. First, the oxide on the backside is etched in BHF, while the front side of the SOI wafer is protected. The backside of the SOI wafer is then etched in a RIE process until the device layer is removed and the cantilever released, Figure 2(h).

The wafer is diced and the chips polarized individually. The polarization directions of the two layers are aligned opposite to each other, i.e. during polarization the top and bottom electrodes are grounded and a polarization voltage is applied to the middle electrode. The dimensions for the final energy harvester chips are shown in Table 1.

\section{Table 1: Energy harvester dimensions.}

\begin{tabular}{|c|c|}
\hline Frame dimensions & $10 \mathrm{~mm} \times 10 \mathrm{~mm}$ \\
\hline Medial dimensions & $<1 \mathrm{~mm}$ \\
\hline Cantilever width & $5.5 \mathrm{~mm}$ \\
\hline Cantilever length & $1.95 \mathrm{~mm}$ \\
\hline Total cantilever height & $2 \times 30 \mu \mathrm{m}$ \\
\hline Mass length & $4.55 \mathrm{~mm}$ \\
\hline
\end{tabular}
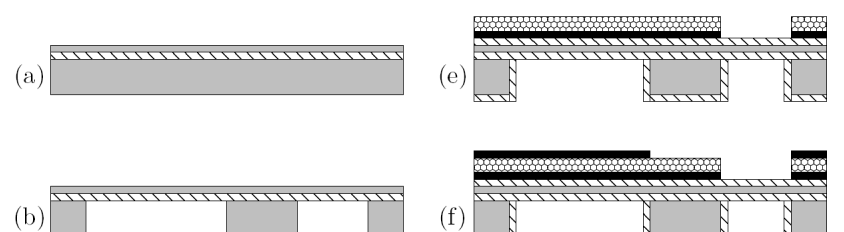

(b)
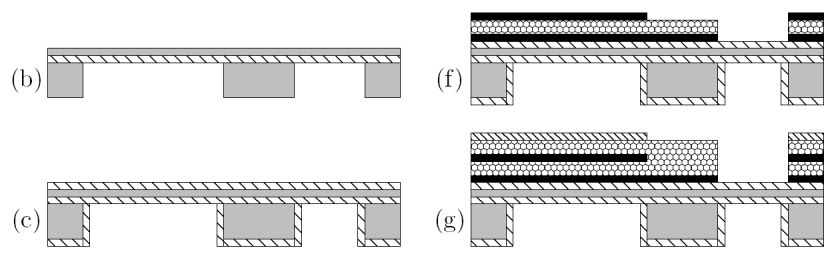

(d)
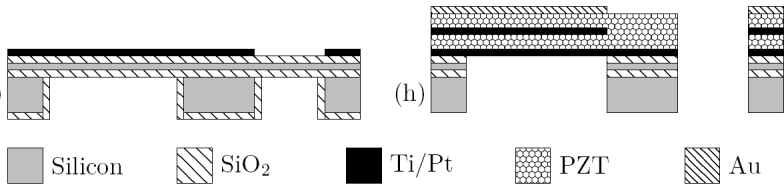

Figure 2: A cross sectional sketch of the process flow for the screen printed PZT/PZT thick film bimorph MEMS energy harvester.

\section{RESULTS}

The fabricated energy harvester was characterized both visually and electrically. The electrical characterization is done by measuring the direct and the indirect piezoelectric effect. The indirect piezoelectric effect was measured using an Agilent 4294A Precision Impedance Analyzer to excite the harvester electrically, and then measure the impedance and the phase.

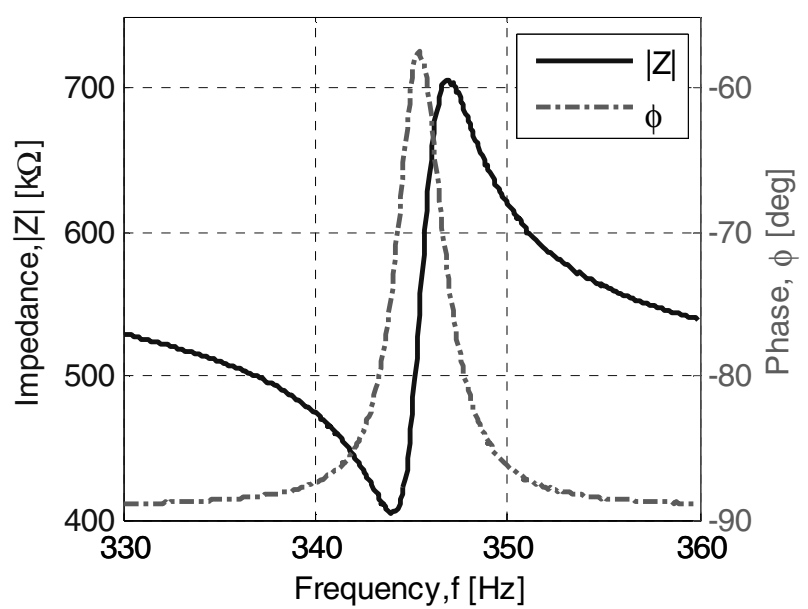

Figure 3: An impedance measurement of the energy harvester probed between the top electrode and the bottom electrode at the resonant frequency.

Figure 3 shows one of such measurements where the bottom electrode and the top electrode are probed. The resonant frequency is $f_{r}=344 \mathrm{~Hz}$ and the anti-resonant frequency is $f_{a}=347 \mathrm{~Hz}$. The impedance at resonance is the optimal resistive load $R_{\text {opt }}=405 \mathrm{k} \Omega$. The same measurements were done between the bottom and middle electrode and between the middle and top electrode. Even though the resonant and anti-resonant frequency stays the same, the optimal resistive load will change mainly due to the change in the layer thickness. The optimal resistive 
load between bottom and middle electrode is $R_{\text {opt }}=179 \mathrm{k} \Omega$. The optimal resistive load between middle and top is $R_{\text {opt }}=345 \mathrm{k} \Omega$.

The direct piezoelectric effect is measured using the aforementioned resistive loads in a shaker setup. The harvester is actuated by a B\&K Mini Shaker 4810 driven by an amplified sinusoidal signal from an Agilent 33220A function generator. A B\&K Piezoelectric Accelerometer 8305 is mounted on the shaker along with the harvester. The acceleration from the shaker was measured by the accelerometer and is stated in fractions of the gravitational acceleration $g\left(9.81 \mathrm{~m} \mathrm{~s}^{-2}\right)$. Since the PZT layers are polarized in opposite directions, the power output of both layers was measured with the top electrode and the bottom electrode, connected by the resistive load $R_{\text {opt }}=405 \mathrm{k} \Omega$. By measuring the RMS voltage drop across the load the dissipated power can be calculated as $P_{r m s}=V_{r m s}{ }^{2} / R_{o p t}$. Figure 4 shows the power output as a function of the excitation frequency. A maximum power of $7.35 \mu \mathrm{W}$ was measured at an acceleration of $1 \mathrm{~g}$. The asymmetric shape of the power peak and the decrease in resonant frequency with increasing power is probably due to a non-linear response of PZT under stress; with increasing stress in PZT the material's effective Young's modulus and the quality factor decreases [22]. The decrease in Young's modulus decreases the spring constant and thus also the resonant frequency.

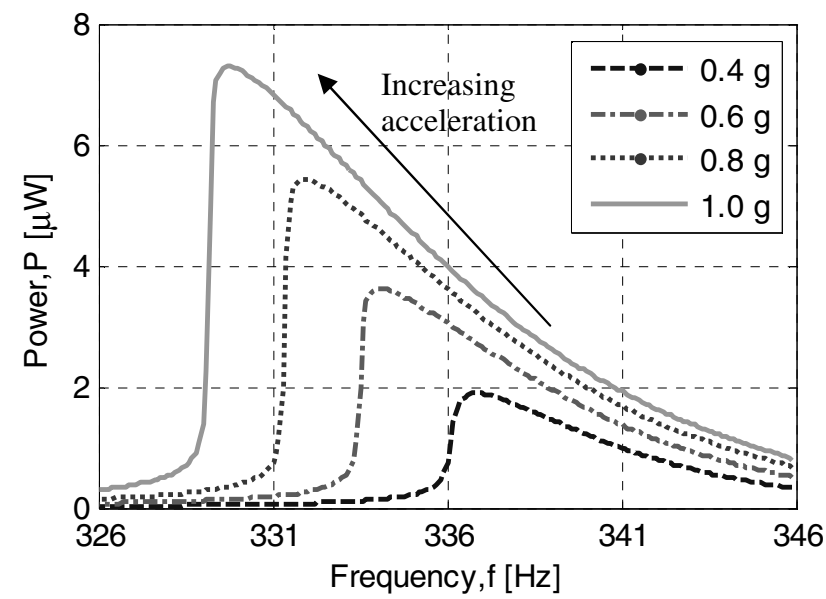

Figure 4: Power output as a function of the excitation frequency for different accelerations. The top electrode was connected to the bottom electrode through a resistive load, $R_{\text {opt }}=405 \mathrm{k} \Omega$, optimized for maximum power using the impedance analyzer measurements.

During measurements of the power output of the top PZT layer, the top electrode and the middle electrode was connected through the resistive load of $R_{\text {opt }}=345 \mathrm{k} \Omega$, while the bottom electrode is kept in open circuit. In a similar to measurement of the power output of the bottom PZT layer the resistive load of $R_{\text {opt }}=179 \mathrm{k} \Omega$ was used, and the top electrode was kept in open circuit. Similar measurements to those shown in Figure 4 are done on the top and bottom PZT layer. The power output from these measurements at resonant frequency are collected and plotted against the input acceleration, as shown in Figure 5 . Figure 5 shows that the power output is indeed higher when both layers are measured, but it is not the sum of the power outputs from the other two layers. This is caused by the factor that when more power is extracted from the harvester the more electrically damped the system becomes and thus yields lower power.

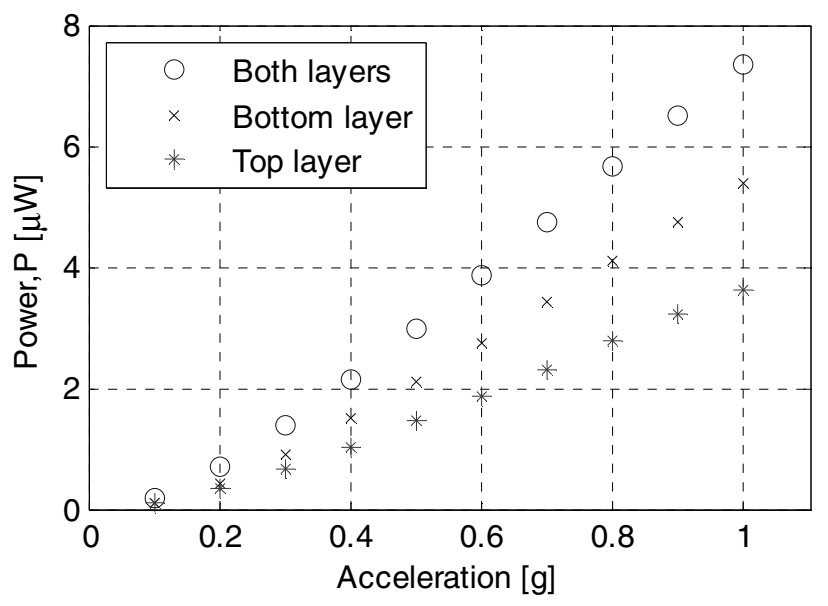

Figure 5: The power output from the top PZT layer, the bottom PZT layer and both layers at resonant frequency as a function of the input acceleration.

The difference in optimal resistive load and power output from the bottom and the top PZT layer is caused by mismatch in PZT film thickness and material properties, which is confirmed by inspection of the cantilever cross section using scanning electron microscopy (SEM). Figure 6 shows the cross section of the PZT/PZT cantilever, and illustrates clearly the undesirable layer mismatch. Besides the bottom PZT layer is thinner than the top layer, the grains of the bottom layer appear to be larger.

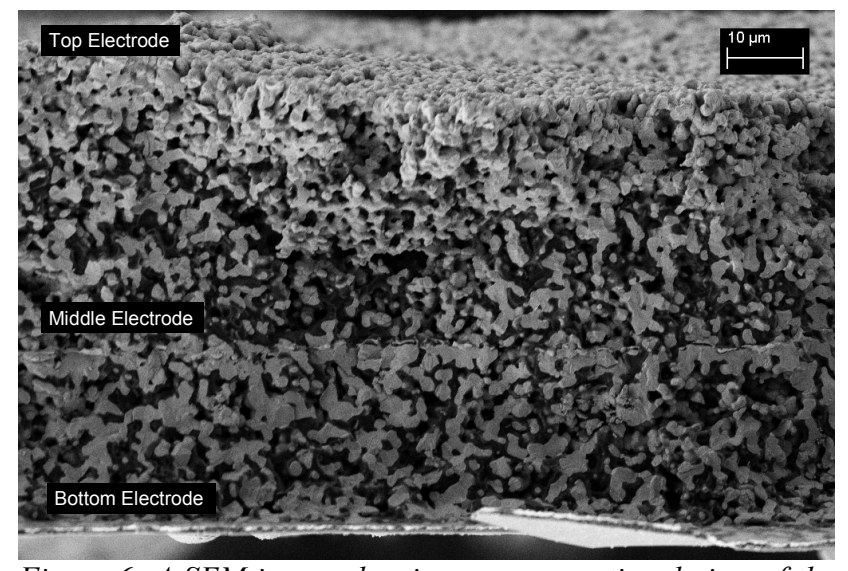

Figure 6: A SEM image showing a cross sectional view of the PZT/PZT bimorph cantilever. The middle electrode separates the two PZT layers. 


\section{CONCLUSION}

Screen printed PZT/PZT thick film bimorph MEMS cantilever energy harvesters were successfully fabricated and characterized. By replacing the inactive cantilever support with another layer of PZT more power is indeed harvested compared to the power harvested from each individual layer. At $1 \mathrm{~g}$ the power output from both layers combined is $7.35 \mu \mathrm{W}$, while the power output for the individual layers at same input acceleration are $5.39 \mu \mathrm{W}$ for the bottom layer and $3.62 \mu \mathrm{W}$ for the top layer.

\section{ACKNOWLEDGEMENTS}

This research is part of the ELBA project, which is funded by the Advanced Technology Foundation. Center for Individual Nanoparticle Functionality (CINF) is sponsored by Danish National Research Foundation.

\section{REFERENCES}

[1] N. S. Hudak, G. G. Amatucci, "Small-scale energy harvesting through thermoelectric, vibration, and radiofrequency power conversion", Journal of Applied Physics, 103, 2008.

[2] S. P. Beeby, M. J. Tudor, and N. M. White, "Energy harvesting vibration sources for Microsystems applications," Measurement Science and Technology, vol. 17, no. 12, pp. R175-R195, 2006.

[3] K. A. C.-Chennault, N. Thambi, A. M. Sastry, "Powering MEMS portable devices - a review of nonregenerative and regenerative power supply systems with special emphasis on piezoelectric energy harvesting systems", Smart Materials and Structures, vol. 17, pp. 1-33, 2008.

[4] E. Lefeuvre, A. Badel, C. Richard, L. Petit, D. Guyomar, "A comparison between several vibration powered piezoelectric generators for standalone systems", Sensors and Actuators A 126, pp. 405-416, 2006.

[5] Hua-Bin Fang et al., "Fabrication and performance of MEMS-based piezoelectric power generator for vibration energy harvesting", Microelectronics Journal, 37:1280-1284, 2006.

[6] W.J. Choi, Y. Jeon, S.G. Kim, "Energy harvesting MEMS device based on thin film piezoelectric cantilevers", Journal of Electroceramics, 17, 2006.

[7] Dongna Shen et al., "The design, fabrication and evaluation of a MEMS PZT cantilever with an integrated $\mathrm{Si}$ proof mass for vibration energy harvesting", Journal of Micromechanics and Microengineering, vol. 18, 2008.

[8] Swee-Leong Kok, Neil M. White, Nick R. Harris, "Fabrication and characterization of free-standing thick-film piezoelectric cantilevers for energy harvesting", Measurement Science and Technology, 20, 2009.

[9] John G. Gualtieri, John A. Kosinski, Arthur Ballato, "Piezoelectric Materials for Acoustic Wave Applications", IEEE Transactions on Ultrasonics, Ferroelectrics, and Frequency Control, Vol 41 no. 1,
1994.

[10] G. Carlotti, G. Socino, A. Petri, E. Verona, "Elastic Constancs of Sputtered ZnO Films", Ultrasonics Symposium, p. 295-299, 1987.

[11] M. A. Dubois, P. Muralt, "Measurement of the effective transverse piezoelectric coefficient e31 of AlN and $\mathrm{Pb}\left(\mathrm{Zr}_{\mathrm{x}}, \mathrm{Ti}_{\mathrm{x}-1}\right) \mathrm{O} 3$ thin films", Sensors and Actuators A, Vol.77, p. 106-112, 1999.

[12] R Elfrink, T M Kamel, M Goedbloed,S Matova, D Hohlfeld, Y van Andel, R van Schaijk, "Vibration energy harvesting with aluminum nitride-based piezoelectric devices", Journal of Micromechanics and Microengineering. Vol. 19, 2009.

[13] Y. Liao, H. A. Sodano, "Model of a single mode energy harvester and properties for optimal power generation", Smart Materials and Structures, vol. 17, no. 6, p. 065026,2008

[14] A. Erturk, D. J. Inman, “An experimentally validated bimorph cantilever model for piezoelectric energy harvesting from base excitations," Smart Materials and Structures, vol. 18, no. 2, p. 025009, 2009.

[15] H. Jacobsen, H. Quenzer, B. Wagner, K. Ortner, and T. Jung, "Thick PZT layers deposited by gas flow sputtering," Sensors and Actuators A: Physical, vol. 135, no. 1, pp. 23-27, Mar. 2007.

[16] D. Shen et al., "Micromachined PZT cantilever based on SOI structure for low frequency vibration energy harvesting," Sensors and Actuators A: Physical, vol. 154, no. 1, pp. 103-108, Aug. 2009.

[17] H. Fang et al., "Fabrication and performance of MEMS-based piezoelectric power generator for vibration energy harvesting," Microelectronics Journal, vol. 37, no. 11, pp. 1280-1284, Nov. 2006.

[18] C. Hindrichsen, R. Lou-Møller, K. Hansen, and E.Thomsen, "Advantages of PZT thick film for MEMS sensors," Sensors and Actuators A: Physical, vol. 163, no. 1, pp. 9 - 14, 2010.

[19] R. Lou-Moeller et al., "Screen-printed piezoceramic thick films for miniaturised devices," Journal of Electroceramics, vol. 19, no. 4, pp. 333-338, 2007.

[20] A. Lei, R. Xu, A. Thyssen, A.C. Stoot, T. L. Christiansen, K. Hansen, R. Lou-Moeller, E.V. Thomsen and K. Birkelund, "MEMS-Based Thick Film PZT Vibriational Energy Harvester", Proceeding, IEEE micro electro mechanical systems, 2011, pp. 125-128.

[21] R.G. Ballas, "Piezoelectric Multilayer Beam Bending Actuators", Springer, 2007.

[22] D. Shen, J. Park, J. Ajitsaria, S. Choe, H. C. Wikle, and D. Kim, "The design, fabrication and evaluation of a MEMS PZT cantilever with an integrated Si proof mass for vibration energy harvesting", Journal of Micromechanics and Microengineering, vol. 18, no. 5, p. 055017, 2008.

\section{CONTACT}

Ruichao Xu, tel: +45-45255692;

RUICHAO.Xu@NANOTECH.DTU.DK 